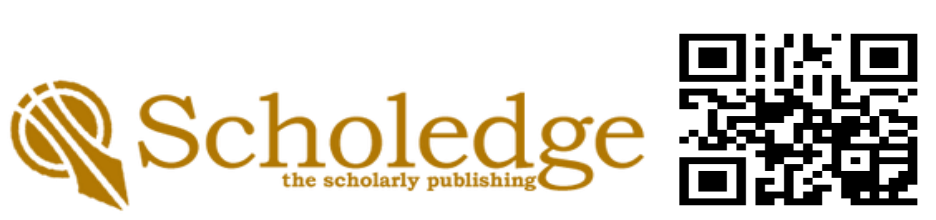

SCHOLEDGE INTERNATIONAL JOURNAL OF MULTIDISCIPLINARY \& ALLIED STUDIES VOL. 2, ISSUE 4 (APRIL 2015) ISSN-2394-336X

\title{
EMOTIONAL INTELLIGENCE AND JOB SATIFICATION AMONG UNIVERSITY TEACHERS
}

\author{
Hafsa Ahmed \\ QAU, Islamabad, Pakistan.
}

\begin{abstract}
The study aimed to explore the relationship of emotional intelligence on the job satisfaction among university teachers. This research was descriptive in nature .The research objectives included to study the relationship between emotional intelligence and job satisfaction among university teachers and to explore the role of demographic variation such as age, gender, experience, qualification of the university teachers in determining their level of emotional intelligence and their perception about job satisfaction. The population of this study was university teachers of public and private sector universities in Islamabad. A stratified random sample comprised of fifty male and fifty female university teachers were collected from two public and two private universities of Islamabad. Two questionnaires were used for data collection in which one for measuring Job satisfaction while other for measuring emotional intelligence (selfawareness, social skills, self-regulation, motivation, social awareness) of prospective teachers. Data was analyzed with the help of SPSS 16. The major finding of the study concludes that is positive significant correlation between Emotional intelligence and Job satisfaction among public and private sector universities $(\mathrm{r}=0.78)$. Result showed that female university teachers are more emotional intelligent than male university teachers whereas male university teachers perceive greater job satisfaction. However, Older university teachers are more emotionally intelligent and perceives greater job satisfaction.
\end{abstract}

Result concluded that lecturers are more emotional intelligent while Professor perceives higher job satisfaction. Result portrays that PHD qualified university teachers shows more emotional intelligence while $\mathrm{PhD}$ qualified teachers perceives greater job satisfaction. Findings conclude that less experienced university teachers are more emotional intelligent whereas experienced university teachers perceives greater job satisfaction. It further discloses that a private sector university teachers experiences higher emotional intelligence whereas public sector university teacher recognizes higher job satisfaction The study was beneficial to teachers, researchers, curriculum developer, trainers, psychologists and education planners. Job satisfaction among teachers can be enhanced by training, needs satisfaction, providing facilities and improving their emotional intelligence.

KEYWORDS: Emotional intelligence, Job satisfaction, university teachers, self-awareness, social skills, self-regulation, motivation, social awareness.

\section{INTRODUCTION}

The most crucial factor for achievement of goals, success and development of any organization is human resource development. In education organization, human resources are committed, reliable, hardworking, favorable working atmosphere and skilled personal. For accomplishing the goals of any institute, the essential circumstances must be provided so that the workforces will achieve their allocated task in favorable atmosphere with inclination and 
satisfaction and have the required productivity in attaining the organizational goals.

Job satisfaction is an indispensable part of administrative environment and important aspect in organization worker association. It is an optimistic emotional situation that happens

Job satisfaction is a product of sentimental reaction of a worker to his/her work; this sentimental reaction is an outcome of anticipated effect from the employees job (Jorfi \& Jorfi, 2011). Job satisfaction is a degree to which an individual be fond of his effort.

Job satisfaction is an expressive association a worker has with his work (Tett \& Meyer, 2006). It is a behavior presented by a worker during this/her working time, hence the mechanisms of serenity and anger deviates with time. Various studies by (Kosteas, 2007) designates that promotion is an instrument to enhance job satisfaction. An individual having an outstanding educational vocation, vigorous work experience and sufficient appreciation in work environment is theoretically considered a key source to an organization.

A vital element related to job satisfaction is to have taken care for every teacher's emotions, beliefs, feelings and social values. The word "Emotional Intelligence" first coined by Salovery \& Mayer, (1990). Emotional Intelligence states to the expertise of establishing the thoughts intelligently. Emotional Intelligence denotes to frame of attained capability and abilities that anticipate constructive outcome at residence, in institute, in the operational and functional atmosphere (Smith, L, Heaven, \& Ciarroch, 2008). Organizational force having these abilities, generally from the standpoint of Emotional intelligence are less disappointed, extremely dynamic working environment and appreciates spectacular interactions .

Emotional Intelligence is one of important factor of social science that has significant influence on the teacher's performance in educational organization. Teachers are the key pillar in the educational hub. Teachers serve as moderators for transfer of knowledge to the students who are foundation when a worker's work seems to achieve fundamental occupation values allocated such values is in placement with individual needs (Jorfi, Yaccob, \& Shah, 2011). Job satisfaction is widely studied in both academics and industries and coined as "a pleasing expressive state from the assessment of one's work or experience". of nation development. Skilled, talented and knowledgeable teachers provide operational source of information. In current era, the concept of emotional intelligence has taken great significance among educational institution. Emotional intelligence is like social intelligence that control own and others sentiments while make a choice among them and the capacity of consuming these sentiments to set his existence. Therefore, effective teacher performance depends upon this skill that allows teachers not only able to deal with their apprentices but with their coworkers as well.

In framework of Emotional Intelligence model, self-observed competency to discover, scrutinize, explore, observe, evaluate, establish and regulate the sentiments of the person. Various researches have determined that Emotional Intelligence has been playing significant role in modern working atmosphere (Nordin, 2012). The viewpoint of Emotional Intelligence supports in investigating worker's attitude, styles of supervision and management, interactive competences and abilities. It affirms significance in HR practices like planning, recruitment, selection and reporting (Serrat, 2009). The most vital advantage of EI is that it benefits the university teachers to understand and accomplish thoughts. It also delivers a ground to a individual to become manageable of his own behavior as well as relationship with the other people (Mayer \& Salovery, 1993).Various research revealed that, understanding and dealing sentiments play vital and fundamental role in satisfying person's daily life and working environment (Cooper \& K, 1993).

The overall perception acclaims the university teachers with excellent emotional intelligence could enjoy higher level of job satisfaction (Ealias \& Jijo , 2012).The universal belief that individual who are blessed with greater emotional intelligence can accomplish the expressing approaches to apprehend the 
likely bewildering circumstances resulting in apprehension. On the other hand individuals with average emotional intelligence will not be moderately accomplishing the overcoming unfulfilled instances. Moreover, employees with brilliant emotional intelligence are predictable to govern the sentiments of the individuals around in a way that they will be able to place all their dynamisms into their work and to make others receiving excitement (Cooper \& K, 1993).

Numerous researches about the relationship between Emotional intelligence and Job satisfaction have explained diversified assumptions. Some researchers have enumerated strong to average association between Emotional intelligence measures and job satisfaction (Kafetsios \& Zampetakis, 2008). Another research reveals significant positive association between Emotional intelligence and Job satisfaction (Trivellas, Gerogiannis, \& Svarna, 2013,).

Since the contrary outcomes of the research conceded out so far on emotional intelligence and job satisfaction and in view of association between job satisfaction and emotional intelligence. The present study seeks to find the answer to such questions as whether there is any relationship between emotional intelligence as well as its components (Selfawareness. Motivation, Self-Regulation, Social Awareness and Social Skill) and job satisfaction of university teachers. Lastly, it strive for outcome whether there is a significant difference between emotional intelligence and job satisfaction of university teachers in terms of age, gender, experience, and educational degree. STATEMENT OF THE PROBLEM

Present research was designed to explore the relationship between emotional intelligence and job satisfaction among university teachers. It further intended to examine the role of university teacher; demographic variation, such as, qualification, experience, gender and sector in the emotional intelligence and job satisfaction in the classroom situation.

\section{RESEARCH OBJECTIVES}

1. To study the relationship between emotional intelligence and job satisfaction among university teachers
2. To explore the role of demographic variation among university teachers in a working environment influences the job satisfaction and emotional intelligence.

\section{RESEARCH HYPOTHESES}

H1: There is significant relationship in the emotional intelligence and job satisfaction among university teachers.

H2: Job satisfaction in the working atmosphere enhances the level of emotional intelligence.

H3: There is a difference in the perception of university teachers about the job satisfaction due to demographic variations such as gender, age, qualification etc.

H4: There is a difference in the level of emotional intelligence due to variations in age, gender and qualification among university teachers.

\section{RESEARCH DESIGN:}

The study was descriptive in nature so survey method was adopted.

\section{POPULATION}

The study population from which the sample was drawn for the study consists of all males and females teachers of public and private universities working at Islamabad.

\section{SAMPLE:}

A stratified random sample consists of 100 university teachers was collected from four universities (two public, two private) located at Islamabad. It is process of dividing whole sample into strata and selecting random sample from it. The sample of 100 university teachers was divided into four strata where each stratum consists of twenty five respondents from particular university. The universities from which sample was taken were Quaid-e-Azam University , International Islamic University, National University of Computer \& Emerging Sciences and National Universty of Science and Technology . The data was collected from two public universities from which sample is taken are Quaid-e-Azam University and National 
University of Science and Technology where as International Islamic University, National University of Computer \& Emerging Sciences are two private universities.

\section{RESEARCH INSTRUMENT}

The research instrument used for collection of data was questionnaire. EI questionnaire containing 28 items was used for the measurement of an emotional intelligence measuring five subscales such as self-awareness, social skills, self-regulation, motivation, social awareness and Wysocky and Kromm's Job Description Index contains 41 questions measuring job satisfaction. The respondents give their agreement and disagreement on 5 Likert scale with response category (strongly disagree 1, disagree 2, neutral 3 , agree 4 , and strongly agree 5).

\section{DATA COLLECTION}

The data collected for the study through questionnaire by personal visits on each university teachers.

\section{Table 1}

Inter Scales Correlations of Emotional intelligence with its Subscales and Total scale $(\mathrm{N}=\mathbf{1 0 O})$

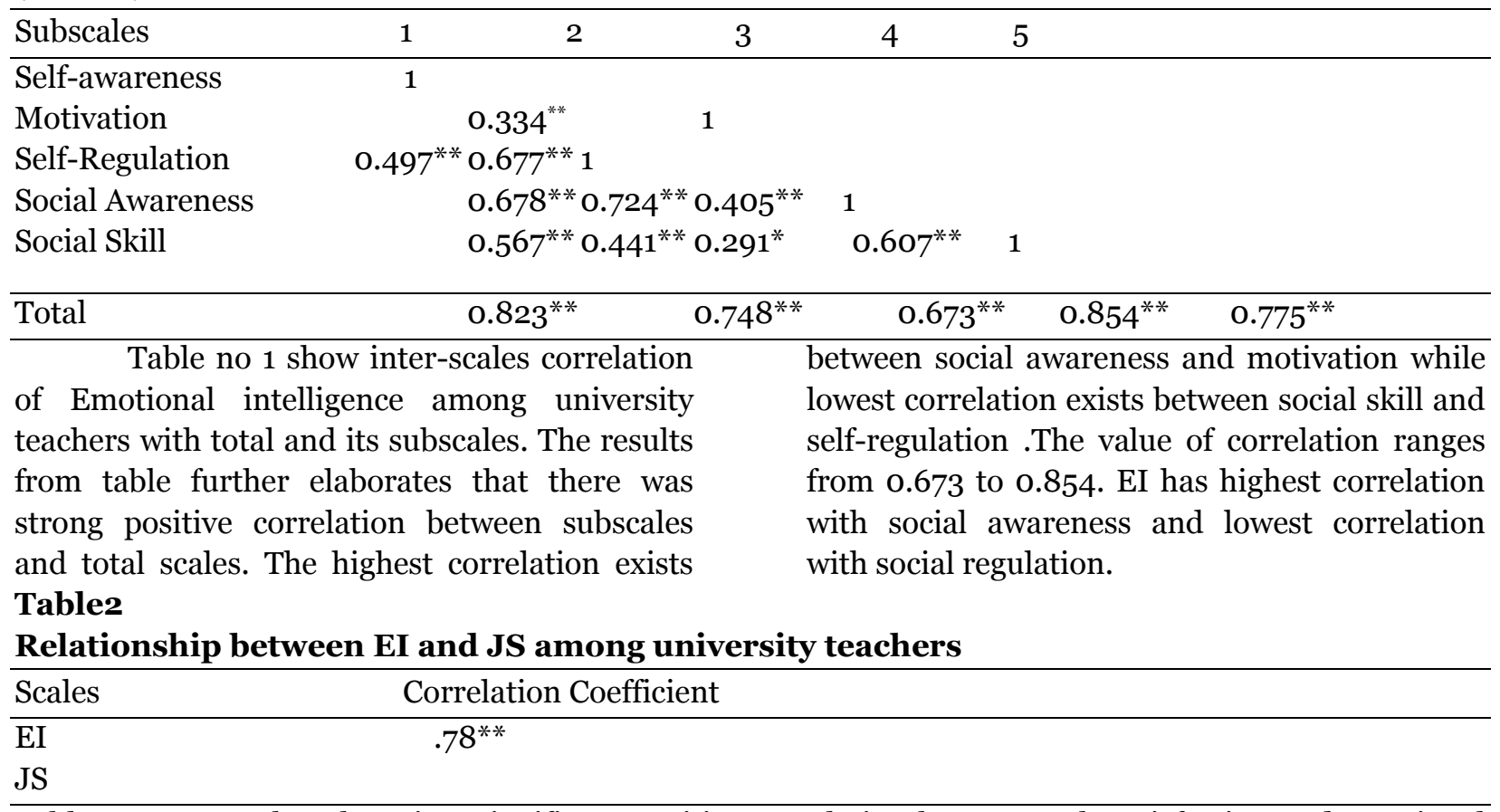

Table 2 portrays that there is a significant positive correlation between Job satisfaction and emotional intelligence.

Table 3

\section{DATA ANALYSIS}

Data collected from questionnaire was analyzed with the help of SPSS 16 software. In order to determine the effect of demographic variation among university teachers in a working environment influences the job satisfaction and emotional intelligence and seek out psychometric properties for research instruments different statistical techniques were applied like mean, Standard deviation, Conbrach Alpha Reliability and ANOVA.

\section{RESULTS}

The research aimed to explore the relationship of emotional intelligence and job satisfaction among university teachers .The research was carried on the sample of 50 males and 50 females university teachers of public and private universities in Islamabad. Reliability of EI and JS was calculated through Conbrach Alpha Reliability. The reliability of EI questionnaire was 0.8234 and reliability of JS questionnaire was 0.867 . It exposes that instrument has highly reliable to measure the relationship of Emotional Intelligence and Job satisfaction among university teachers. 
Comparison of Mean and Standard Deviation of Emotional Intelligence and Job Satisfaction among University teachers for variable "Gender" $(N=10 o)$

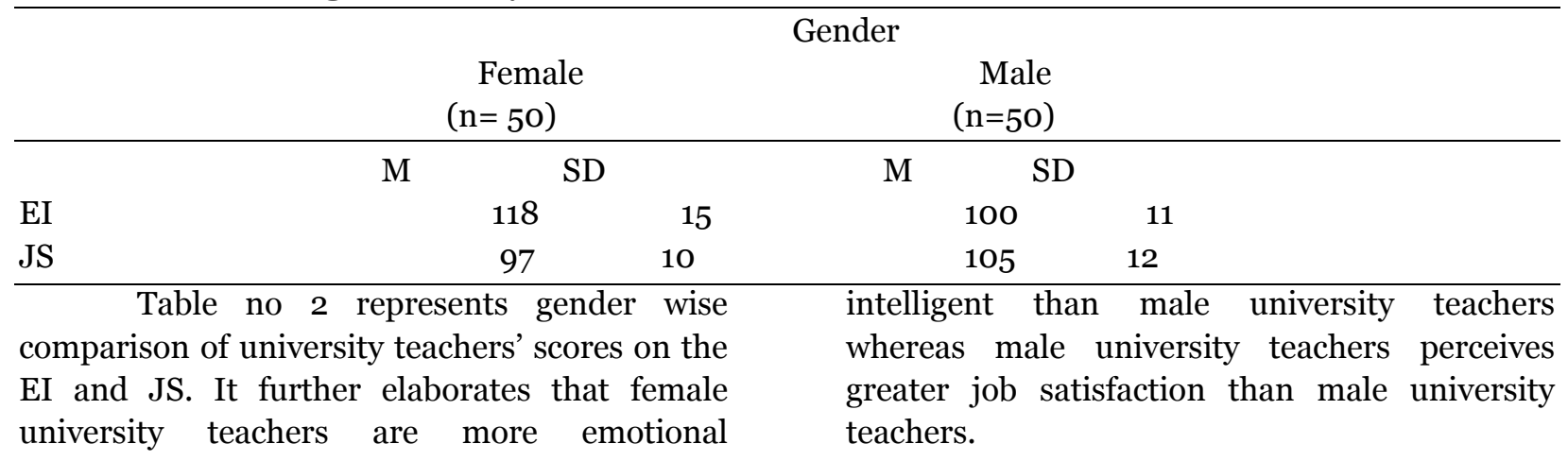

Table 4

One way Analysis of variance of University teacher scores on EI and JS for the variable Gender

\begin{tabular}{|c|c|c|c|c|}
\hline ANOVA of ICT & $\mathrm{DF}$ & Mean Squares & $\mathrm{F}$ & Sig \\
\hline Between Groups & 1 & 98.14 & 4.987 & 0.04 \\
\hline Within Groups & 48 & 20.53 & & \\
\hline Total & 49 & & & \\
\hline
\end{tabular}

Table 3 indicates that there is significant difference between the responses of university teachers belonging to both genders about

Emotional Intelligence and Job satisfaction. The value of $\mathrm{F}$ ratio is 4.987 and level of significance is 0.04 which is less than 0.05 .

Table 5

Comparison of Mean and Standard Deviation of Emotional Intelligence and Job Satisfaction among University teachers for variable “Age" $(N=100)$

\begin{tabular}{|c|c|c|c|c|c|c|c|}
\hline & & & & Age & & & \\
\hline Subscales & 20-3 & & $31-40$ y & & $41-50 y$ & & \\
\hline Of ICT & $(n=3$ & & $(n=47)$ & & & $(n=2$ & \\
\hline & $\mathrm{M}$ & SD & $\mathrm{M}$ & SD & $\mathrm{M}$ & SD & \\
\hline EI & 125 & 15 & 130 & 18 & & 150 & 22 \\
\hline JS & 110 & 9 & 126 & 14 & & 120 & 12 \\
\hline
\end{tabular}
are more emotionally intelligent as compared to

Table 6

Comparison of Mean and Standard Deviation of University teachers scores of EI and JS for variable "Designation" $(N=100)$

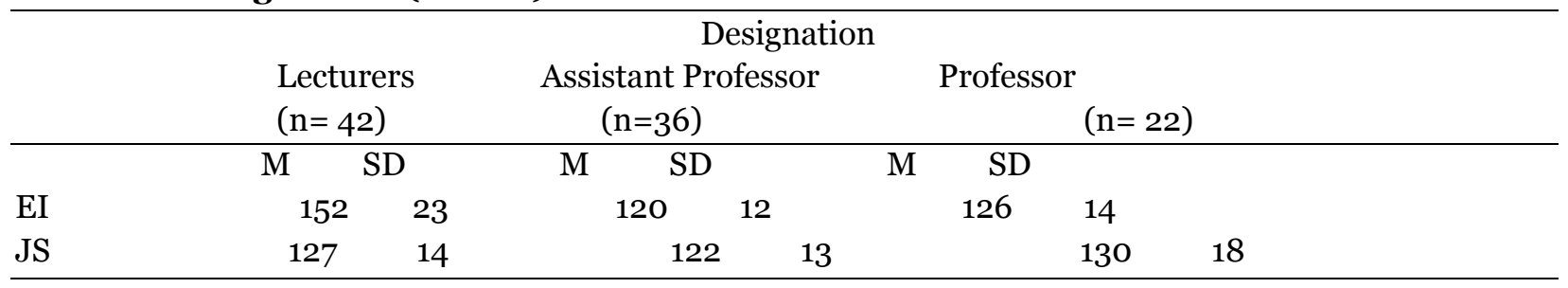


Table no 6 indicates designation wise comprasion of university teachers scores. The result from table shows that university lecturers are more emotional intelligent as compared to other designation level while professor perceives higher job satisfaction as compared to others.

Table 7

Comparison of Mean and Standard Deviation of University teachers of EI and JS for variable "Qualification" $(N=10 o)$

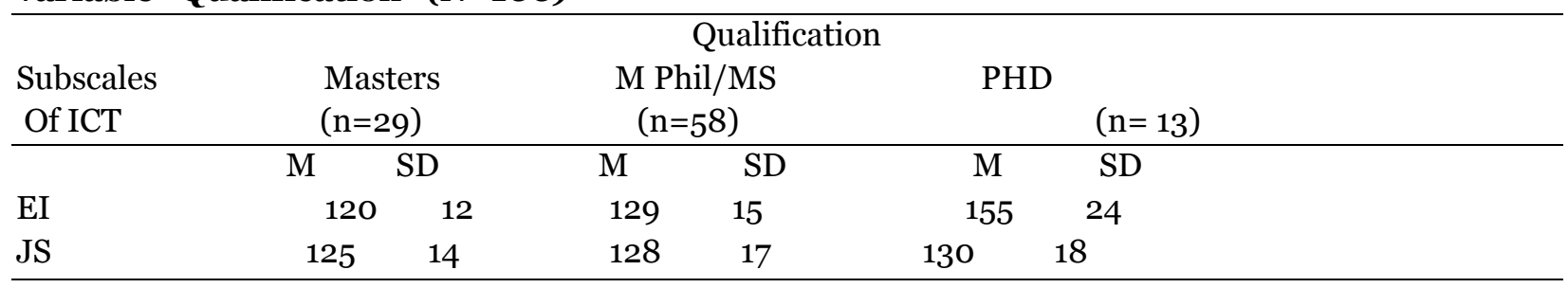

Table no 7 shows comparison of university teacher's scores of Emotional and Job Satisfaction. The outcome indicates that the university teachers having $\mathrm{PhD}$ are more emotional intelligent as compared to with other qualification levels. It further illustrates that $\mathrm{PhD}$ qualified university teachers perceives greater job satisfaction.

Table 8

Comparison of Mean and Standard Deviation of University faculty scores of EI and JS for variable "Experience" $(\mathrm{N}=100)$

\begin{tabular}{lcccccc}
\hline & \multicolumn{4}{c}{ Experience } \\
& $\begin{array}{c}1-10 \text { yrs } \\
(\mathrm{n}=32)\end{array}$ & $\begin{array}{c}11-20 \text { yrs } \\
(\mathrm{n}=38)\end{array}$ & \multicolumn{2}{c}{$>20 \mathrm{yr}$} \\
$(\mathrm{n}=30)$
\end{tabular}

Table no 8 shows experience wise comprasion of university faculty on EI and JS. The result portrays that the less experienced university teachers are more emotional intelligent than experienced university teacher while more experienced university teachers perceives higher job satisfaction than less experienced university teachers.

\section{Table 9}

Comparison of EI and JS of public and private sector university teachers for variable "Nature of Institution" ( $N=100)$

\begin{tabular}{|c|c|c|c|c|c|}
\hline & & \multicolumn{4}{|c|}{ Nature of Institution } \\
\hline & \multirow{2}{*}{\multicolumn{2}{|c|}{$\begin{array}{l}\text { Public } \\
\qquad(n=50)\end{array}$}} & Priv & \multirow{2}{*}{\multicolumn{2}{|c|}{$(n=50)$}} \\
\hline & & & & & \\
\hline & $\mathrm{M}$ & SD & M & & \\
\hline EI & & 118 & 128 & & \\
\hline JS & & 125 & & 120 & 12 \\
\hline
\end{tabular}

Table no 9 portrays the results of comprasion among public and private sector universities of Emotional intelligence and Job satisfaction .The results illustrates that the private sector university teachers have more emotional intelligence as compared to the public sector universities . It further discloses that a public sector university teacher perceives higher job satisfaction than private sector university teachers.

\section{Discussion and conclusion}

The research aimed to explore the relationship of emotional intelligence on the job 
satisfaction among university teachers. The study was mainly based on research objectives. First, objective of the research was to study the relationship between emotional intelligence and job satisfaction among university teachers and to explore the role of demographic variation among university teachers in a working environment influences the job satisfaction and emotional intelligence.

The reliability of EI was 0.8234 and reliability of JS was 0.867 which shows that instrument has highly reliable to measure the relationship of Emotional Intelligence and Job satisfaction among university teachers. The results illustrates that all the subscales of EI are positively correlated. The correlation scores is $0.78^{* *}$ which portrays that there is a significant positive correlation between Job satisfaction and emotional intelligence

Result portrayed the gender difference in prospective university teachers perceptions where female university teachers are more emotional intelligent than male university teachers whereas male university teachers perceives greater job satisfaction than male university teachers. Result showed that older university teachers are more emotionally intelligent as compared to young university teachers as far as their perception about job satisfaction is considered more in middle age university teachers. Result revealed that university lecturers are more emotional intelligent as compared to other designation level while professor perceives higher job satisfaction as compared to others designation. Result portrayed that PhD qualified university teachers are more emotional intelligent as compared to with other qualification levels. It further illustrates that $\mathrm{PhD}$ qualified university teachers perceives greater job satisfaction.

Result illustrated that the less experienced university teachers are more emotional intelligent than experienced university teacher while more experienced university teachers perceives higher job satisfaction than less experienced university teachers. The result concludes that the private sector university teachers have more emotional intelligence as compared to the public sector universities. It further discloses that a public sector university teacher perceives higher job satisfaction than private sector university teachers. There is evidence that emotional intelligence affects job satisfaction of university teachers. Findings of the study are also consistent with Thomas and Tram (2006), Millet (2007), Kafetsios and Zampetakis (2007), Casper (2007), Hasankhoyi (2006) and Hosseinian et al. (2008).

\section{RECOMMENDATION}

The research findings provide a significance of emotional intelligence in order to enhance job satisfaction .Following recommendation is given on basis of findings.

1. There may be launched EI awareness programs in the university in order to improve the EI among university teachers.

2. University may have supervisory support and assessment for university teachers to accomplish educational goal.

3. Universities may provide supervisory support to develop the relationship and foster cooperation among university teachers and increases the level of job satisfaction.

4. University may provide promotions in order to encourage university teachers and increase the level of job satisfaction.

5. Private sector universities should increase the level of job satisfaction among teachers.

\section{REFERENCES}

- Cooper, \& K, R. (1993). EQ Map: Interpretation Guide. San Francisco: AIT and Essi Systems.

- Elias, M. J. (2009). Social-Emotional and Character Development and Academics as Dual Focus of Educational Policy. New Jersey: Sage Publication.

- Jorfi, H., Yaccob, H. F., \& Shah, I. M. (2011). the relationship between demographics variables, emotional intelligence, communication effectiveness motivation, and job satisfaction. International Journal of Academic Research in Business and Social Sciences 1(1), 35-58. 
- Jorfi, H. \& Jorfi,S. (2011). Strategic Operations Management: Investigating the Factors Impacting Communication Effectiveness and Job Satisfaction. Social and Behavioral Sciences.

- Kosteas, V. D. (2007). Job Satisfaction and Promotions. Ohio: Northeast Ohio Economics Workshop and the Midwest Economics Association.

- Kafetsios, K., \& Zampetakis, L. A. (2008). Emotional intelligence and job satisfaction: Testing the mediatory role of positive and negative affect at work. Personality and Individual Differences, 44(8), 712-722.

- Mayer, J. D., \& Salovey, P. (1993). The intelligence of emotional intelligence. Intelligence, 17, 433-442

- Nordin, N. (2012). The influence of leadership behavior and organizational commitment on organizational readiness for change in a higher learning institution. Asia Pacific Education Review, 13(2), 239-249.

- Smith, L. M., Heaven, P. C. L., \& Ciarrochi, J. (2008). Trait emotional intelligence, conflict communication patterns, and relationship satisfaction. Personality and Individual Differences, 44, 1314-1325.

- Serrat, O. (2009). Understanding \& Developing Emotional Intelligence. Washington DC: Asian Development Bank.

- Salovery, P., \& Mayer, J. D. (1990). Emotional intelligence. Baywood Publishing, 185-200.

- $\quad$ (Salovey, P., \& Argyris, C. (2011). Emotional Intelligence and Leadership. Global Health Faculty Symposium (pp. 1-14). New Haven: USA.

- Trivellas, P., Gerogiannis, V., \& Svarna, S. ( 2013). Exploring workplace implications of Emotional Intelligence (WLEIS) in hospitals: Job satisfaction and turnover Intentions. Procedia Social and Behavioral Sciences, 73 (2013) 701-709.

- Tett, R. P., Fox, K. E., \& Wang, A. (2005). Development and validation of a self-report measure of emotional intelligence as a multidimensional trait domain. Personality and Social Psychology Bulletin, 31, $859-888$

- Tett, R. P., \& Meyer, J. P. (2006, December 7). online Liberary. Retrieved from Wiley online Liberary:http://onlinelibrary.wiley.com / 